\title{
Usefulness of PET-CT in the evaluation of suspected recurrent ovarian carcinoma
}

\author{
Mona Abdel Ghaffar ElHariri ${ }^{1 *}$, Mervat Harira ${ }^{2}$ and Mohamed M. Riad ${ }^{3}$
}

\begin{abstract}
Background: The purpose of the current study is to assess the PET/CT potential value in the diagnosis of ovarian cancer recurrence.

Results: PET/CT scan described suspicion of ovarian cancer (OC) recurrence in 20 local pelvic lesions with 100\% sensitivity, accuracy, and specificity and in 18 peritoneal lesions with sensitivity and specificity of 76.19 and 95.65 and accuracy of $89.55 \%$. While PET/CT suspected OC recurrence in 5 pelvic, 9 para-aortic, and 10 distant lymph nodes, the sensitivity, specificity, and accuracy were (80, 98.38, and $97 \%),(66.67,94.82$, and 91.04\%), and (90, 98.24, and 97.01), respectively. PET/CT scan described suspicion of OC recurrence in 5 distant organ metastases; the accuracy, sensitivity, and specificity were 100\%. The lesion-based accuracy, sensitivity, specificity, positive predictive value, and negative predictive value of PET/CT scan were $95.77,85.7,97.89,90.5$ and $97 \%$ while the corresponding patient-based values were $94.44,96.87,75$, and $94.44 \%$ and 96.87 and $75 \%$.
\end{abstract}

Conclusion: PET-CT is a helpful modality in the assessment of OC recurrence; it can detect and localize the recurrence with high accuracy, thus can influence and modify the treatment plan, and reduces the need for 2nd look surgery.

Keywords: PET, PET-CT, CT, Malignancy, Ovarian, Recurrence

\section{Background}

Ovarian cancer is the second most frequent gynecologic malignancy (preceded by cervix carcinoma) with up to 25 and $75 \%$ chance of 2 years' recurrence of early and advance stages respectively. Thus, the early recurrence detection is crucial for planning of the treatment roadmap aiming to have a better life quality with longer period of disease-free condition [1-7].

The serial assessment of CA-125 (serum tumor marker) level is broadly used for the monitoring of the tumor recurrence; however, lack of the site and size information and non-specificity for ovarian cancer (OC) (around $20 \%$ of OC is CA-125 negative) are all considered as limitation and disadvantages [7-9].

OC recurrence imaging approaches include $\mathrm{CT}$ and MRI modalities; however, the main OC metastases are to the peritoneal rather than the parenchymal way which

\footnotetext{
* Correspondence: Doctormona2000@yahoo.com

${ }^{1}$ Department of Radio-diagnosis, Faculty of Medicine, Zagazig University, PO. BOX 184, Zagazig, Sharkia 44511, Egypt

Full list of author information is available at the end of the article
}

makes the detection of small implanted tumor on the visceral surface challenging [5-7].

Non-invasive functional imaging using PET (positron emission tomography) is broadly applied in imaging of tumor. It can image the consumption of glucose based on the principle that the tumor cells with metabolic activity will show more glucose uptake than normal cells due to its higher glucose consumption by increased glycolysis as well as increased cell membrane glucose transporter molecules numbers. The most widely used PET radiotracer is 18F-fluorodeoxyglucose (FDG). 18-FDG being a glucose analogue can enter the tumor cells and phosphorylated by hexokinase without further glucose metabolism, thus becoming trapped in tumor cells allowing the spatial localization and active sites detection [10-14].

Thus, FDG can be a very sensitive indicator for glucose-avid cancers. However, inflammatory and infectious processes also show high FDG [10-14].

Because of the poor anatomical resolution of PET images due to anatomical landmarks lacking and physiologic tracer distributions, a combination of PET and CT images can be done by the use of an integrated system 
of PET/CT which can provide precise anatomical location of FDG-PET active lesions on CT map [13-16].

The purpose of the current study was to assess the potential value of $\mathrm{PET} / \mathrm{CT}$ in ovarian cancer recurrence detection.

\section{Materials and methods}

This prospective study was approved by the institutional review board, and the informed consent from the patient was taken.

\section{Patients}

Thirty-six patients with suspected recurrent ovarian malignancy on clinical base, raised CA-125 levels, or US, $\mathrm{CT}$, or MRI suspected changes.

For the patients who had a second-look surgery, it was done in less than 7 weeks of imaging investigations with 3.4 weeks median interval with PET/CT.

All patients had at least $5 \mathrm{~h}$ fasting except in diabetic patients (4h fasting), and they could have their insulin just before fasting.

Scanning was not done unless the blood glucose was below $200 \mathrm{mg} / 100 \mathrm{ml}$. IV injection of additional $20 \mathrm{mg}$ furosemide was given to increase the urinary tract diagnostic accuracy as well as reduce its radiation dose.

$\mathrm{PET} / \mathrm{CT}$ was started $60 \mathrm{~min}$ following IV injection of about $5 \mathrm{MBq} / \mathrm{kg}$ body wt of FDG (maximum $550 \mathrm{MBq}$ ) during that interval; the patient was instructed to be in supine rest to avoid the non-specific uptake by muscles.

\section{The technique of PET/CT}

PET-CT scanning of whole-body scanning was done using Biograph PET-CT scanner (Siemens) with multislice CT (64-slice). It was obtained starting from the skull base to the level of mid of the thigh.

The CT study was performed firstly followed by the PET component. CT parameters: $140 \mathrm{KV}, 80-100 \mathrm{~mA}$, collimation of $5 \mathrm{~mm}$, rotation time $(0.5 \mathrm{~s})$, and pitch 0.984 . The patients were placed in a supine position with arms up if possible to prevent artifact with instruction to keep a normal respiration. Nonionic contrast media $(2 \mathrm{ml} / \mathrm{kg}, 5 \mathrm{ml} / \mathrm{s})$ were administered intravenously just prior to CT (in 29 patients). Reconstruction was done to obtain $1.2 \mathrm{~mm}$ slice thickness.

PET scan was subsequently done in 5-7 bed positions (each takes $5 \mathrm{~min}$ ). Attenuation correction of PET data was done by using the data of CT acquisition. Reconstruction of 18FDG-PET images was done with $4.5 \mathrm{~mm}$ thickness. Dedicated workstation was used in the revision of PET, CT, and fused PET/CT images.

\section{Image interpretation}

Analysis of axial and multiplanar images of CT, PET, and fused PET/CT images was performed for ovarian carcinoma recurrence. Revision of bone and lung windows images was done.

Qualitative and quantitative SUV max (the standard maximum uptake value) which represents dose in tissue/ injected dose) was evaluated for each focal abnormal uptake of radiotracer (focal activity higher than the soft tissue background).

Using CT, the focal FDG uptake was localized as either (a) local pelvic recurrence, (b) peritoneal, (c) lymphadenopathy (pelvic, para-aortic, or distant), and (d) metastatic disease.

\section{Standard of reference}

The gold standard was a histopathology study (27 patients) done within 4 weeks of PET/CT through either surgery (20 patients) or biopsy (7 patients). Surgery was conducted by a specialized team (oncology, gynecologic, and surgical), and detailed intraoperative and histopathological report was used as reference standard.

The remaining 9 patients without pathological confirmation were monitored at least 6 months through serial measuring of CA-125 and radiological studies. Patients treated with second-line chemotherapy was considered as positive (5 cases) if the initial high serum CA-125 returned to normal by completion of chemotherapy with clinical improvement and tumor size regression at imaging follow-up while considered negative (4 cases) with stable serum CA-125 level and imaging in the follow-up for 6 months or more.

\section{Statistical analysis}

The data was analyzed using SPSS for Windows version 10. The accuracy, sensitivity, specificity, positive predictive value (PPV), and negative predictive value (NPV) of each of PET and PET/CT report were estimated, and comparison was done. Results were compared using McNemar's test and $T$ test was done. Statistical significance was considered if $P$ value $<0.05$.

\section{Results}

Thirty-six patients with suspicion of ovarian cancer recurrence were enrolled in this study with mean age of $53.5 \pm 7.4$ years. The mean level of serum CA- 125 was $129 \pm 148 \mathrm{U} / \mathrm{ml}$ (range $5-879 \mathrm{U} / \mathrm{ml}$ ) (CA-125 up to 30 $\mathrm{U} / \mathrm{ml}$ was considered as normal).

Thirty-two patients were with serous papillary adenocarcinoma; two, clear cell tumor; and two, undifferentiated carcinoma.

Based on FIGO classification, the patients were classified as follows: FIGO I $(n=3,8.3 \%)$, FIGO II $(n=4$, $11.1 \%)$, FIGO III $(n=22,61.1 \%)$, and FIGO IV $(n=7$, 19.4\%).

According to the final diagnosis, 32 patients had a recurrent $\mathrm{OC}$ while 4 patients were negative for recurrent $\mathrm{OC}$. 
Confirmation of positive cases was done by histopathological study of the resected tumor (20 cases) and biopsy (7 patients) with pelvic and distant metastases. The rest of cases (5 cases) with no available pathological confirmation were confirmed by the drop of initially high level of serum CA-125 after secondline chemotherapy with clinical improvement and tumor regression at imaging through at least 6 months follow-up.

The 4 negative cases were confirmed depending on the stable level of serum CA-125 and radiological imaging after the second-line chemotherapy for 6 months or more follow-up.

The PET-CT scan was positive in $32 / 36$ subjects (true-positive $=31$ cases and false-positive $=1$ case). Four cases were negative at $\mathrm{PET} / \mathrm{CT}$ scan (true-negative $=3$ cases and false-negative $=1$ case) .

Sixty-seven lesions were described at PET/CT scan with suspicion of $\mathrm{OC}$ recurrence of which 20 lesions in the pelvis, 18 peritoneal lesions, 5 pelvic, 9 para-aortic and 10 distant lymph nodes, and 5 distant organs (Tables 1 and 2).

\section{A. Local pelvic recurrence (Fig. 1)}

PET/CT scan described suspicion of OC recurrence in 20 lesions in the pelvis. The sensitivity, accuracy, and specificity were $100 \%$ for local pelvic recurrence diagnosis.

\section{B. Peritoneal metastasis}

$\mathrm{PET} / \mathrm{CT}$ scan described the suspicion of OC recurrence in 18 peritoneal lesions (it had two and five falsepositive and false-negative lesions, respectively) with sensitivity and specificity of 76.19 and 95.65 and accuracy of $89.55 \%$.

C. Lymph nodes
i. Pelvic lymph nodes

Table 1 Positive lesions at PET/CT compared to final results

\begin{tabular}{llll}
\hline $\begin{array}{llll}\text { Form of } \\
\text { recurrence }\end{array}$ & $\begin{array}{l}\text { PET/CT positive } \\
\text { lesions }\end{array}$ & Final results & \\
\cline { 3 - 4 } Pelvic recurrence & 20 & Present & Absent \\
Peritoneal & 18 & 2 & 20 \\
Distant organ & 5 & 0 & 16 \\
Lymph nodes & & & 5 \\
$\quad$ Pelvic LN & 5 & 1 & 4 \\
Para-aortic & 9 & 3 & 6 \\
Distant LN & 10 & 1 & 9 \\
Total & 67 & 7 & 60 \\
\hline
\end{tabular}

Table 2 PET/CT performance in the diagnosis of various recurrence forms of ovarian cancer

\begin{tabular}{llll}
\hline Form of recurrence & Accuracy (\%) & Sensitivity (\%) & Specificity (\%) \\
\hline Pelvic & 100 & 100 & 100 \\
Peritoneal & 89.55 & 76.19 & 95.65 \\
Distant organ & 100 & 100 & 100 \\
Lymph nodes & & & \\
$\quad$ Pelvic LN & 97 & 80 & 98.38 \\
$\quad$ Para-aortic & 91.04 & 66.67 & 94.82 \\
$\quad$ Distant LN & 97.01 & 90 & 98.24 \\
Total & 95.77 & 85.7 & 97.89 \\
\hline
\end{tabular}
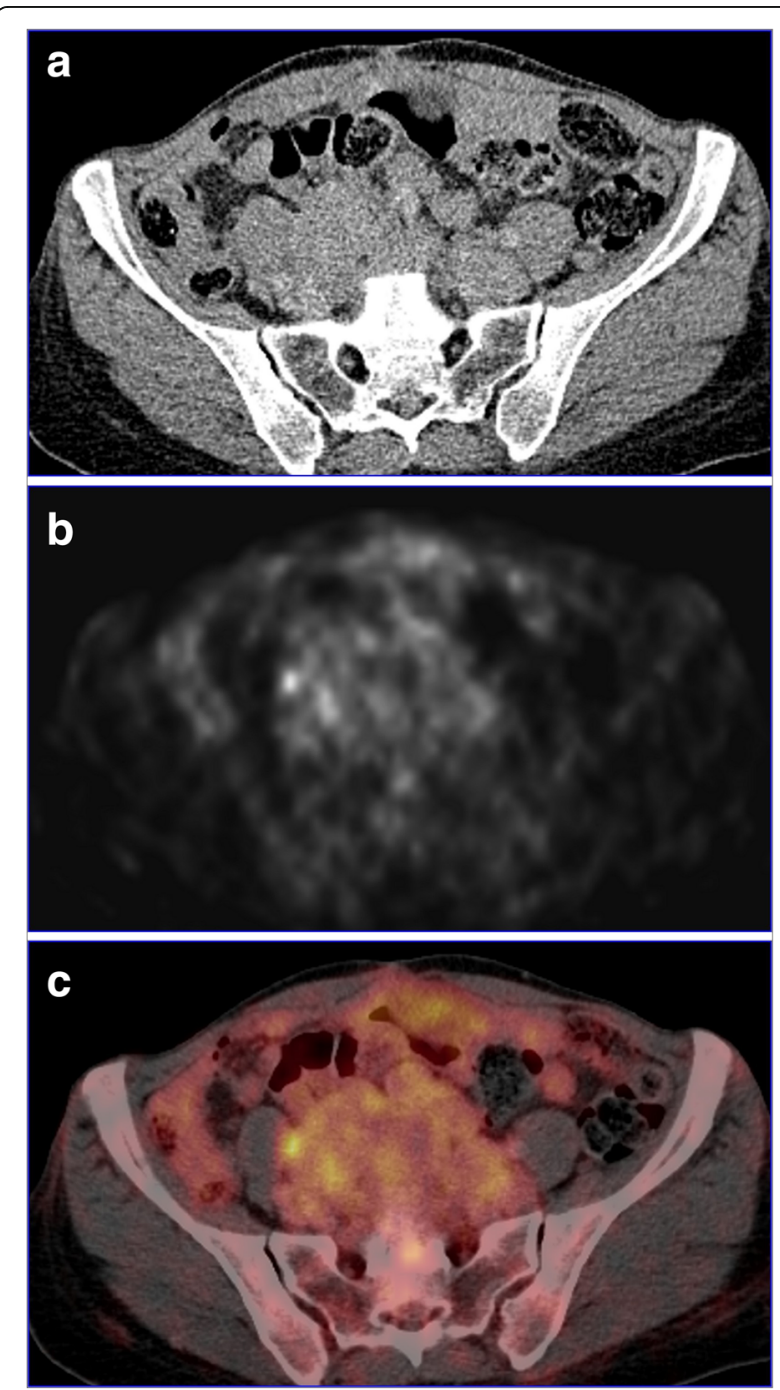

Fig. 1 Recurrent ovarian cancer. a Axial contrast-enhanced $C T$, b FDG PET, and c PET/CT images show multiple confluent soft tissue heterogeneous masses with increased FDG uptake (max. SUV 6) 
PET/CT scan described the suspicion of OC recurrence in 5 pelvic lymph nodes (one false-positive and one false-negative lesion) with sensitivity, specificity, and accuracy of $80,98.38$, and $97 \%$, respectively.

ii. Para-aortic lymph nodes (Fig. 2)

PET/CT scan described suspicion of OC recurrence in 9 para-aortic lymph nodes (3 false-positive and similar
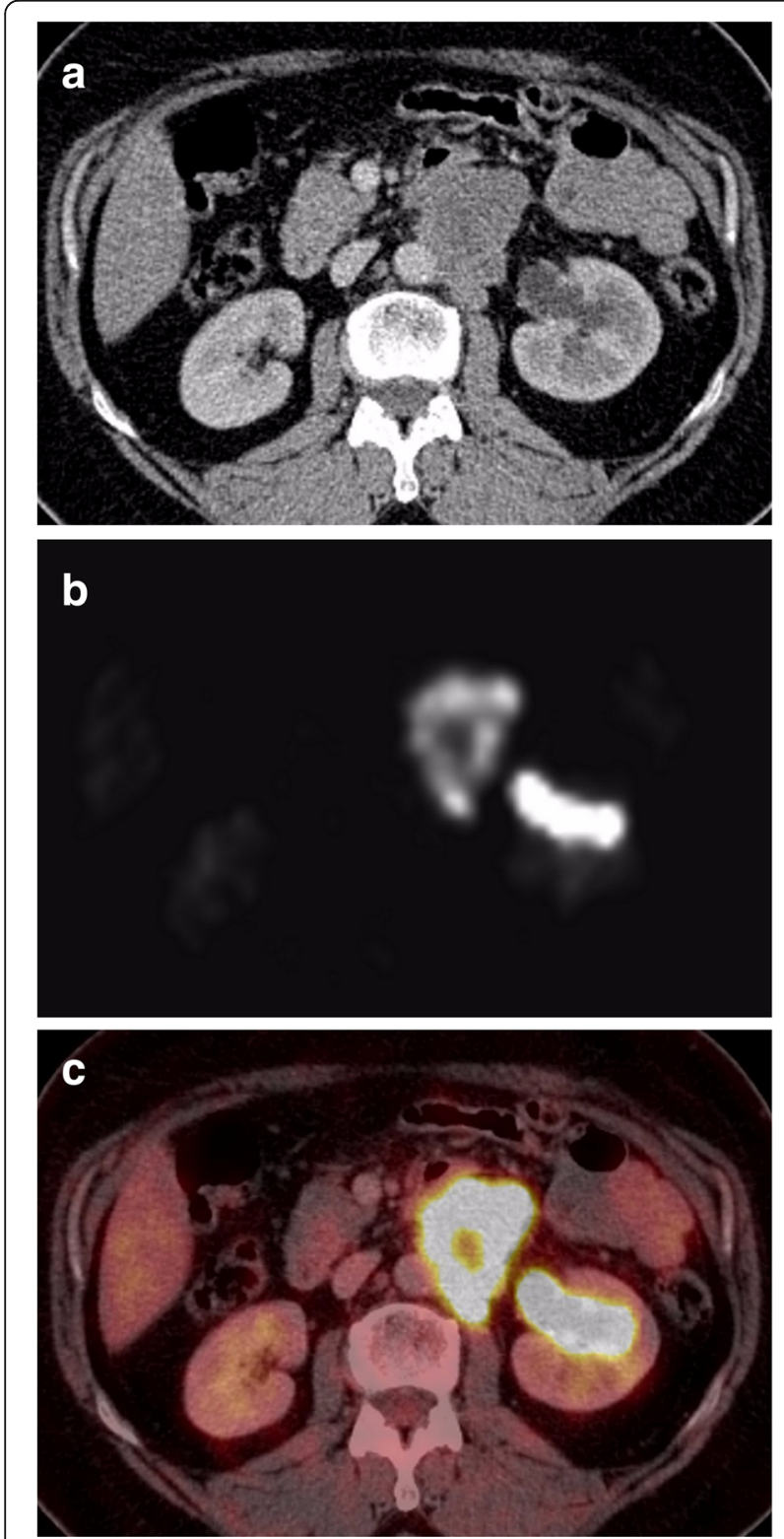

Fig. 2 Para-aortic lymph node metastasis. a Axial contrast-enhanced CT, b FDG PET, and $\mathbf{c}$ PET/CT show enlarged amalgamated left paraaortic lymph nodes with intense FDG uptake (max. SUV 22). Moderated left renal backpressure due to its encasement and compression of the proximal left ureter number was false-negative cases) with sensitivity, specificity, and accuracy of $66.67,94.82$, and $91.04 \%$ respectively.

iii. Distant lymph node metastasis (Fig. 3)

$\mathrm{PET} / \mathrm{CT}$ scan described the suspicion of OC recurrence in 10 distant lymph node metastases ( 1 case was false-negative, one case false-positive) with sensitivity and specificity of 90 and $98.24 \%$ and accuracy of $97.01 \%$.

\section{Distant organ metastases (Figs. 4 and 5)}

PET/CT scan described the suspicion of OC recurrence in 5 distant organ metastases with sensitivity, specificity, and accuracy of $100 \%$.
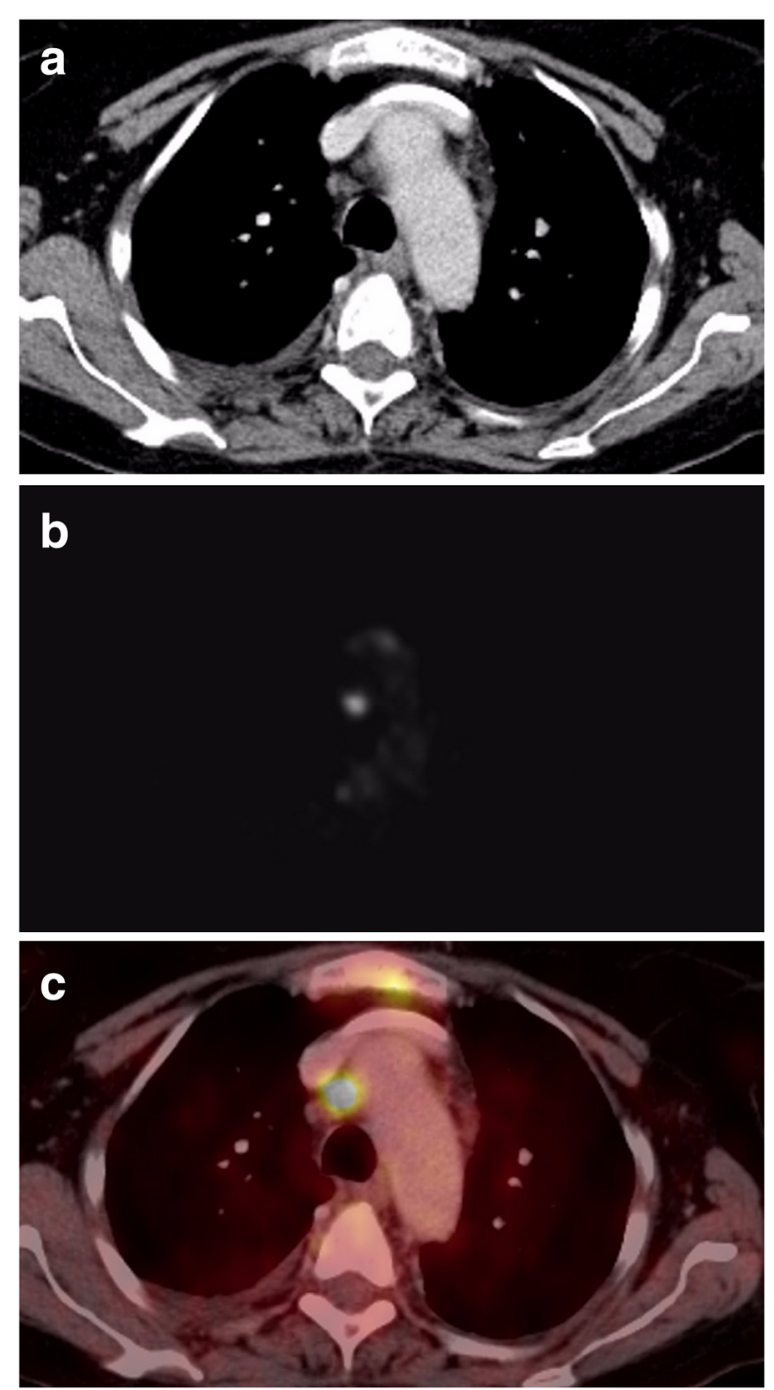

Fig. 3 Mediastinal lymph node metastasis. a Axial contrastenhanced CT, b FDG PET, and $\mathbf{c}$ fused PET/CT show enlarged paratracheal lymph node with markedly FDG uptake (max. SUV 18) 

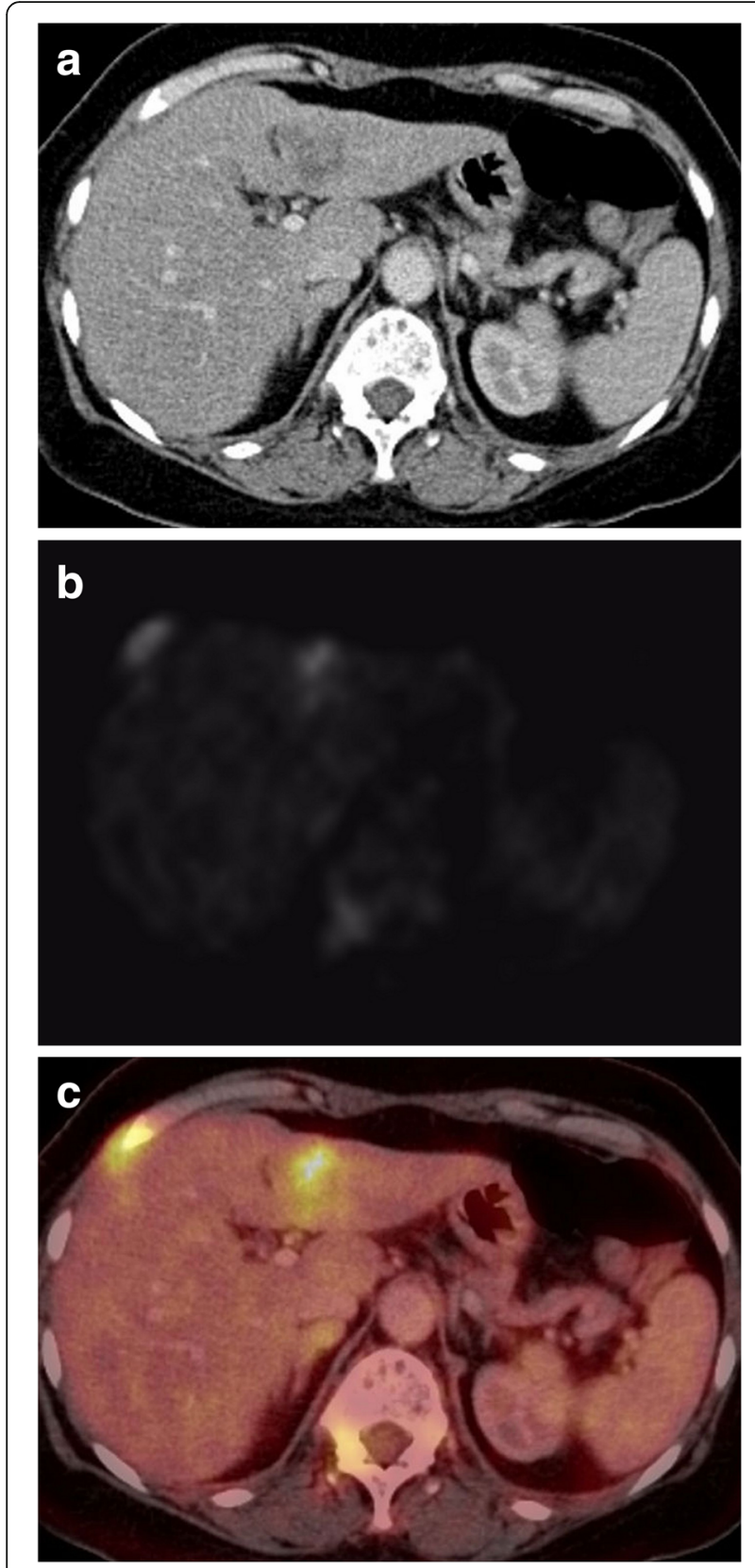

Fig. 4 Liver metastasis. a Axial contrast-enhanced CT, b FDG PET, and $\mathbf{c}$ fused PET/CT show left hepatic lobe focal lesion with marked FDG uptake (max. SUV 14)
The lesion-based overall sensitivity and specificity of PET/CT scan were 85.7 and $97.89 \%$ and accuracy was 95.77\%. PPV $=90.5 \%, \mathrm{NPV}=97 \%$.

The patient-based overall sensitivity and specificity of PET/CT were 96.87 and $75 \%$ and accuracy was $94.44 \%$. $\mathrm{PPV}=96.87 \%$, NPV $=75 \%$ (Table 3 ).

The positive cases showed FDG uptake with SUV range of 3.2 to 27.4 with a mean of 8.3 .
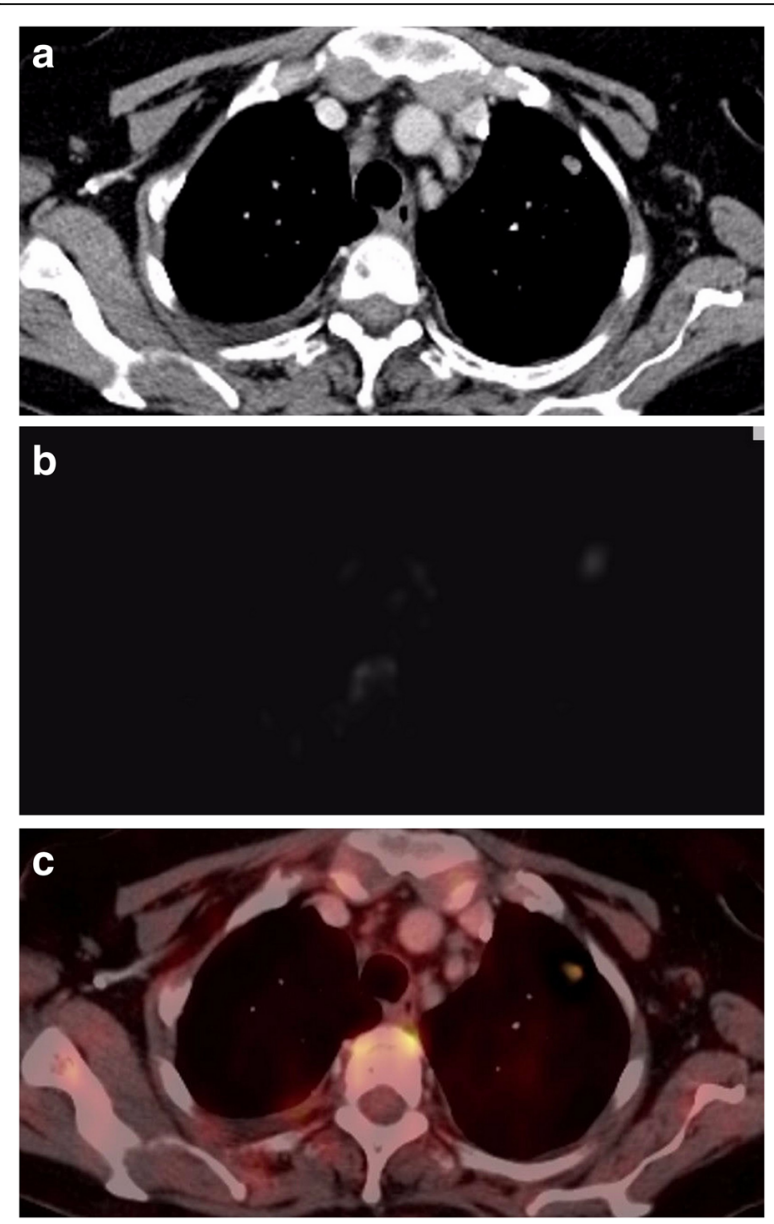

Fig. 5 Lung metastatic nodule. a Axial contrast-enhanced CT, b FDG PET, and $\mathbf{c}$ fused PET/CT show left upper lobe small pulmonary nodule with marked FDG uptake (max. SUV 25)

\section{Discussion}

Owing to its metabolic tracing capability, PET/CT can have a superior role in the detection of ovarian carcinoma recurrence with a power of accurate localization of the lesions; thus, it can alter the treatment plan [17-24].

Some pitfalls may be noted in PET-CT such as respiratory artifacts affecting the upper abdomen as well as normal physiologic uptake (loops of bowel and urinary bladder) $[8,24]$.

False-positive result is another problem as seen in the atherosclerotic plaques, inflammatory bowel process, and myomatosis [24, 25].

On the other hand, false-negative can be gained in ovarian clear cell carcinoma (due to low cellular glucose metabolism) as well as in cystic or necrotic lesions [8, 24, 25].

In the study of Fulham et al. [20] which was carried on 90 ladies with suspicion of ovarian carcinoma recurrence, $\mathrm{PET}-\mathrm{CT}$ displayed a superior detection rate that was achieved by contrast CT which subsequently modified the treatment in $60 \%$ of cases. 
Table 3 Overall PET/CT performance in OC recurrence

\begin{tabular}{llllll}
\hline Form of recurrence & Sensitivity (\%) & Specificity (\%) & Accuracy (\%) & PPV (\%) & NPV (\%) \\
\hline Patient based & 85.7 & 97.89 & 95.77 & 90.5 & 97 \\
Lesion based & 96.87 & 75 & 94.44 & 96.8 & 75
\end{tabular}

In the current study, 36 subjects with suspicion of ovarian cancer recurrence were subjected to PET-CT. The PET/CT could detect recurrence in 32/36 patients with patient-based overall sensitivity and specificity of 96.87 and $75 \%$ while the accuracy was $94.44 \%$.

On the other hand, in the current report, PET-CT could detect 62/67 recurrent lesions with lesion-based overall sensitivity and specificity of 85.7 and 97.89 and accuracy of $95.77 \%$.

Our results are generally in matching with earlier studies [7, 26-32] which had patient-based specificity, sensitivity, and accuracy of $85-100 \%, 86-100 \%$, and $85-$ $100 \%$, respectively, while at the region level, the sensitivity and specificity ranged from $41-78 \%$ and $75-99 \%$ and accuracy $72-96 \%$.

Antunovic et al. [33] used non-contrast CT in their PET/CT report and had a sensitivity of $72 \%$ and specificity of $81 \%$ for PET/CT in the detection of OC recurrence.

Iagaru et al. [34] divided the lesions of OC recurrence to pelvic and extra-pelvic. They showed that PET-CT had a superior performance in the detection of extrapelvic ones, and they attributed that to the false-negative results due to physiological bladder uptake obscuring the pathological pelvic uptake as well as false-positive results caused by the postoperative inflammatory changes.

On the other hand, Sala et al. [35] showed that PET/ CT had the highest accuracy in the diagnosis of peritoneal lesions and limited in the local pelvis recurrence, distant organ metastases (liver and spleen), and distant lymph nodes (above renal hila), and they attributed this false-negative liver and spleen case to mislabeling rather than a non-visualization of lesion.

In the current study, PET/CT had the highest performance for the diagnosis of recurrent local pelvic lesions and metastases to distant organs, and the sensitivity, specificity, and accuracy of $100 \%$, which was very close to the results of Gouhar et al. [7] who estimated $100 \%$ accuracy, sensitivity, and specificity of PET-CT in the detection of recurrence in the same areas.

False-negative can be seen in small-volume disease (5$7 \mathrm{~mm}$ ), military or diffuse peritoneal metastases [36]. In an earlier study of OC recurrence [7], PET/CT had sensitivity and specificity of $77 \%$ and $96 \%$ and accuracy of $90 \%$ in the detection of peritoneal metastasis.

While in the study of Fulham et al. [20], they detected unsuspected lesions in 61 patients (majority had peritoneal nodal or discrete lesions) while they found 8 subjects with FDG diffuse abdominal uptake (military peritoneal spread).

In the current study, PET/CT scan detected 16 lesions of peritoneal metastasis correctly with sensitivity and specificity of 76.19 and 95.65 and accuracy of $89.55 \%$.

We had 5 false-negative peritoneal cases; 2 falsenegative results had cystic or necrotic lesions without significant FDG uptake; however, follow-up showed the development of multiple peritoneal cystic lesions which were resolved after chemotherapy, while the other 3 false-negative cases developed peritoneal deposits after 5 months; this could be explained by microscopic lesions $[37,38]$. On the other side, we had two cases of falsepositive results with peritoneal metastasis, they had $\mathrm{PET} / \mathrm{CT}$ in less than 5 weeks post-surgery, and finally, it was proved to be a postoperative inflammatory process which is previously described as being generally hard to be differentiated from residual lesions $[25,39,40]$.

$\mathrm{PET} / \mathrm{CT}$ has the power to detect metastasis with increased metabolic activity even in non-enlarged lymph nodes; however, small or necrotic lymph nodes can have false-negative results [41]. In the study of Gouhar et al. [7], for lymph node detection, PET/CT had sensitivity and specificity of $80 \%$ and $99 \%$ and accuracy of $97 \%$ in pelvic lymph nodes and 89\%, 100\%, and 99\% for distant lymph node while the corresponding values were $78 \%$, $96 \%$, and $94 \%$ for para-aortic lymph nodes, respectively.

In our study, PET/CT scan described recurrent lesions in 5 pelvic lymph nodes with sensitivity and specificity of 80 and $98.38 \%$ and accuracy of $97 \%$. We had a falsepositive lesion as well as one false-negative lesion, while it described suspicion of $\mathrm{OC}$ recurrence in 9 para-aortic lymph nodes with sensitivity and specificity of 66.67 and $94.82 \%$ and accuracy of $91.04 \%$ respectively (3 falsepositive and same number for false-negative cases). In distant lymph node metastasis, PET/CT scan described 10 lesions with sensitivity and specificity of 90 and $98.24 \%$ and accuracy of $97.01 \%$ (1 case was falsenegative, one case false-positive).

Our results coincide with the previous studies [22, 23, 42] that found a reliable correlation between PET-CT and surgical findings and showed high sensitivity and specificity for all regions except para-aortic lymph nodes and diffuse peritoneum carcinosis showing sensitivity of 83 and 79\%, respectively. Also, this agrees with Iagaru et al. [34] who showed that PET/CT can assist in diagnosis and management of $\mathrm{OC}$ recurrence through accurate localization and 
extension assessment of recurrence and distant metastases which affect re-staging.

Mangili et al. [31] detected a high sensitivity of PET/ CT compared to contrast CT alone (91\% versus $62 \%$ ) for diagnosis of recurrent $\mathrm{OC}$ with altering the treatment and plan in $44 \%$ of cases.

A meta-analysis done by $\mathrm{Gu}$ et al. [43] found a better ovarian cancer detection recurrence by $\mathrm{PET} / \mathrm{CT}$ compared to CT or MRI (sensitivity of 91 versus 79 and $75 \%$ and specificity of 88 versus 84 and $78 \%$ respectively).

In the study of Fagotti et al. [44] to assess the role of $\mathrm{PET} / \mathrm{CT}$ to predict optimal cytoreduction in recurrent OC, the PET/CT estimated specificity and sensitivity of 56 and $93 \%$ and accuracy $79 \%$, while positive predictive and negative predictive value was $77 \%$ and $83 \%$, and they concluded that PET/CT can efficiently affect the plan of surgical treatment of patients with recurrent OC.

In the study carried out by Simcock et al. [17], PET/ CT had significantly changed the treatment plan of recurrent OC in $57 \%$ of the subjects.

We had some limitation in the current study: first, the gold standard (pathological confirmation) could not be achieved in all areas of FDG uptake as that was not ethically possible, and the second limitation was the small study cohort number.

\section{Conclusion}

The current study showed that PET/CT is a helpful modality in the evaluation of ovarian cancer recurrence; it can detect and localize the recurrence with high accuracy, thus can influence and modify the treatment plan, and reduce the need for the look surgery.

\section{Abbreviations}

FDG: Fluorine-18 fluorodeoxyglucose; PET: Positron emission tomography

\section{Acknowledgements}

Not applicable

\section{Authors' contributions}

EM conceived of the study, participated in its design and coordination, drafted the manuscript, and carried out radiological results. HM participated in the design of the study and sequence alignment as well as participated in the surgical assessment. RM helped in drafting the results and participated in the surgical assessment. All authors read and approved the final manuscript.

\section{Funding}

Not applicable.

\section{Availability of data and materials}

The data that support the findings of this study are available on request from the corresponding author.

\section{Ethics approval and consent to participate}

This study was approved by our institutional review board, and informed consent from the patient included in this study was taken.

Consent for publication

Not applicable

\section{Competing interests}

The authors declare that they have no competing interests.

\section{Author details}

${ }^{1}$ Department of Radio-diagnosis, Faculty of Medicine, Zagazig University, PO. BOX 184, Zagazig, Sharkia 44511, Egypt. '2Department of Obstetrics and Gynecology, Faculty of Medicine, Zagazig University, Zagazig, Egypt. ${ }^{3}$ Department of General Surgery, Faculty of Medicine, Zagazig University, Zagazig, Egypt.

Received: 6 June 2019 Accepted: 2 July 2019

Published online: 05 August 2019

\section{References}

1. Jemal A, Siegel R, Ward E, Hao Y, Xu J, Thun MJ (2009) Cancer statistics: 2009. CA Cancer J Clin 59(4):225-249

2. Goonewardene TI, Hall MR, Rustin GJ (2007) Management of asymptomatic patients on follow-up for ovarian cancer with rising CA-125 concentrations. Lancet Oncol 8(9):813-821

3. Gadducci A, Cosio S, Zola P, Landoni F, Maggino T, Sartori E (2007) Surveillance procedures for patients treated for epithelial ovarian cancer: a review of the literature. Int J Gynecol Cancer: Official J Int Gynecol Cancer Soc 17(1):21-31

4. Cannistra SA (2004) Cancer of the ovary. N Engl J Med 351:2519-2529

5. Pannu HK, Bristow RE, Cohade C, Fishman EK, Wahl RL (2004) PET-CT in recurrent ovarian cancer: initial observations. Radiographics 24:209-223

6. Israel O, Kuten A (2007) Early detection of cancer recurrence: 18FFDG PET/CT can make a difference in diagnosis and patient care. J Nucl Med 48:28S-35S

7. Gouhar GK, Siam S, Sadek SM, Ahmed RA (2013) Prospective assessment of 18F-FDG PET/CT in detection of recurrent ovarian cancer. EJRNM 44:913-922

8. Mee CS, Kwon HH, Young BJ, et al (2002) Usefulness of FDG PET for assessment of early recurrent epithelial ovarian cancer. AJR 179.

9. Santillan A, Garg R, Zahurak ML, Gardner GJ, Giuntoli RL, Armstrong DK, Bristow RE (2005) Risk of epithelial ovarian cancer recurrence in patients with rising serum CA-125 levels within the normal range. J Clin Oncol 23(36):9338-9343

10. El-Hariri MA, Gouhar GK, Refat AM (2012) Integrated PET/CT in the preoperative staging of lung cancer: a prospective comparison of $C T, P E T$ and integrated PET/CT. EJRNM 43:613-621

11. Terezakis S, Yahalom J (2011) PET-computed tomography for radiation treatment planning of lymphoma and hematologic malignancies. PET Clin 6:165-175

12. Beyer T, Townsend DW, Brun T, Kinahan PE, Charron M, Roddy R, Jerin J, Young J, Byars L, Nutt R (2000) A combined PET/ CT scanner for clinical oncology. J Nucl Med 41:1369-1379

13. Ell PJ (2006) The contribution of PET/CT to improved patient management. Br J Radiol 79:32-36

14. Ali TF (2012) Usefulness of PET-CT in the assessment of suspected recurrent colorectal carcinoma. EJRNM 43:129-137

15. Endo $K$, Oriuchi $N$, Higuchi $T$, lida $Y$, Hanaoka H, Miyakubo M, Ishikita T, Koyama K (2006) PET and PET/CT using 18F-FDG in the diagnosis and management of cancer patients. Int J Clin Oncol 11:286-296

16. Schulthess GK, Steinert HC, Hany TF (2006) Integrated PET/CT: current applications and future directions. Radiology 238:405-422

17. Simcock B, Neesham D, Quinn M, Drummond E, Milner A, Hicks RJ (2006) The impact of PET/CT in the management of recurrent ovarian cancer. Gynecol Oncol 103:271-276

18. Soussan M, Wartski M, Cherel P, Fourme E, Goupil A, Le Stanc E, Callet N, Alexandre J, Pecking AP, Alberini JL (2008) Impact of FDG PET-CT imaging on the decision making in the biologic suspicion of ovarian carcinoma recurrence. Gynecol Oncol 108(1):160-165

19. Son H, Khan SM, Rahaman J, Cameron KL, Prasad-Hayes M, Chuang L, Machac J, Heiba S, Kostakoglu L (2011) Role of FDG PET/CT in staging of recurrent ovarian cancer. RadioGraphics 31:569-583

20. Fulham MJ, Carter J, Baldey A, Hicks RJ, Ramshaw JE, Gibson M (2009) The impact of PET-CT in suspected recurrent ovarian cancer: a prospective multi-centre study as part of the Australian PET data collection project. Gynecol Oncol 112:462-468

21. Kitajima K, Murakami K, Yamasaki E et al (2008) Performance of integrated FDG-PET/contrast-enhanced CT in the diagnosis of recurrent ovarian cancer: 
comparison with integrated FDG-PET/ non-contrast-enhanced CT and enhanced CT. Eur J Nucl Med Mol Imaging 35(8):1439-1448

22. Dragosavac S, Derchain S, Caserta NM, DE Souza G (2013) Staging recurrent ovarian cancer with FDG PET/CT. Oncol Lett 5:593-597

23. Nanni C, Rubello D, Farsad M, Franchi R, Toso S, Barile C, Rampin L, Nibale O, Fanti S (2005) 18F-FDG PET/CT in the evaluation of recurrent ovarian cancer: a prospective study on forty-one patients. Eur I Surg Oncol 31(7): 792-797

24. Thrall MM, DeLoia JA, Gallion H, Avril N (2007) Clinical use of combined positron emission tomography and computed tomography (FDG-PET/CT) in recurrent ovarian cancer. Gynecol Oncol 105(1):17-22

25. Prakash P, Cronin CG, Blake MA (2010) Role of PET/CT in ovarian cancer. AJR 194:464-470

26. Hauth EA, Antoch G, Stattaus J, Kuehl H, Veit P, Bockisch A, Kimmig R, Forsting M (2005) Evaluation of integrated whole-body PET/CT in the detection of recurrent ovarian cancer. Eur J Radiol 56(2):263-268

27. Bilici A, Ustaalioglu BB, Seker M, Canpolat N, Tekinsoy B, Salepci T, Ozugur S, Gumus M (2010) Clinical value of 18F-FDG PET/CT in the diagnosis of suspected recurrent ovarian cancer: is there an impact of 18F-FDG PET/CT on patient management? Euro J Nucl Med Mol Imag 37(7):1259-1269

28. Bristow RE, Giuntoli RL 2nd, Pannu HK, Schulick RD, Fishman EK, Wahl RL (2005) Combined PET/CT for detecting recurrent ovarian cancer limited to retroperitoneal lymph nodes. Gynecol Oncol 99(2):294-300

29. Bhosale P, Peungjesada S, Wei W, Levenback CF, Schmeler K, Rohren E, Rohren E, Macapinlac HA, Iyer RB (2010) Clinical utility of positron emission tomography/computed tomography in the evaluation of suspected recurrent ovarian cancer in the setting of normal CA-125 levels. Int J Gynecol Cancer: Official J Int Gynecol Cancer Soc 20(6):936-944

30. Sebastian S, Lee SI, Horowitz NS, Scott JA, Fischman AJ, Simeone JF, Fuller AF, Hahn PF (2008) PET-CT vs. CT alone in ovarian cancer recurrence. Abdom Imaging 33(1):112-118

31. Mangili G, Picchio M, Sironi S, Viganò R, Rabaiotti E, Bornaghi D, Bettinardi V, Crivellaro C, Messa C, Fazio F (2007) Integrated PET/CT as a first-line restaging modality in patients with suspected recurrence of ovarian cancer. Eur J Nucl Med Mol Imaging 34(5):658-666

32. Chung HH, Kang WJ, Kim JW, Park NH, Song YS, Chung JK, Kang SB, Lee HP (2007) Role of 18F-FDG PET/ CT in the assessment of suspected recurrent ovarian cancer: correlation with clinical or histological findings. Eur J Nucl Med Mol Imaging 34(4):480-486

33. Antunovic L, Cimitan M, Borsatti E, Baresic T, Sorio R, Giorda G, Steffan A, Balestreri L, Tatta R, Pepe G, Rubello D, Cecchin D, Canzonieri V (2012) Revisiting the clinical value of 18F-18F-FDG PET/CT in detection of recurrent epithelial ovarian carcinomas: correlation with histology, serum CA-125 assay, and conventional radiological modalities. Clin Nucl Med 37(8): e184-e188

34. lagaru AH, Mittra ES, McDougall IR, Quon A, Gambhir SS (2008) 18F-FDG PET/CT evaluation of patients with ovarian carcinoma. Nucl Med Commun 29:1046-1051

35. Sala E, Kataoka M, Pandit-Taskar N, Ishill N, Mironov S, Moskowitz CS, Mironov O, Collins MA, Chi DS, Larson S, Hricak H (2010) Recurrent ovarian cancer: use of contrast-enhanced ct and PET/CT to accurately localize tumor recurrence and to predict patients' survival. Radiology 257(1):125-134

36. Sironi S, Messa C, Mangili G et al (2004) Integrated FDG PET/CT in patients with persistent ovarian cancer: correlation with histologic findings. Radiology 233(2):433-440

37. Nakamoto Y, Saga T, Ishimori T, Mamede M, Togashi K, Higuchi T, Mandai M, Fujii S, Sakahara H, Konishi J (2001) Clinical value of positron emission tomography with FDG for recurrent ovarian cancer. AJR Am J Roentgenol 176(6):1449-1454

38. Rose PG, Faulhaber P, Miraldi F, Abdul-Karim FW (2001) Positive emission tomography for evaluating a complete clinical response in patients with ovarian or peritoneal carcinoma: correlation with second-look laparotomy. Gynecol Oncol 82(1):17-21

39. De laco P, Musto A, Orazi L, Zamagni C, Rosati M, Allegri V, Cacciari N, AlNahhas A, Rubello D, Venturoli S, Fanti S (2011) 18FFDG PET/CT in advanced ovarian cancer staging: value and pitfalls in detecting lesions in different abdominal and pelvic quadrants compared with laparoscopy. Eur J Radiol 80(2):e98-e103

40. Nanni C, Rubello D, Farsad M, De laco P, Sansovini M, Erba P, Rampin L, Mariani G, Fanti S (2005) (18)F-18F-FDG PET/CT in the evaluation of recurrent ovarian cancer: a prospective study on forty-one patients. Euro I Surg Oncol: The J Euro Soc Surg Oncol Brit Assoc of Surg Oncol 31(7):792-797

41. Choi HJ, Roh JW, Seo SS, Lee S, Kim JY, Kim SK, Kang KW, Lee JS, Jeong JY, Park SY (2006) Comparison of the accuracy of magnetic resonance imaging and positron emission tomography/computed tomography in the presurgical detection of lymph node metastases in patients with uterine cervical carcinoma: a prospective study. Cancer 106(4):914-922

42. Lenhard MS, Burges A, Johnson TR, Stieber P, Kümper C, Ditsch N, Linke R, Friese K (2008) PET-CT in recurrent ovarian cancer: impact on treatment planning. Anticancer Res 28:2303-2308

43. Gu P, Pan LL, Wu SQ, Sun L, Huang G (2009) CA 125, PET alone, PET-CT, CT and MRI in diagnosing recurrent ovarian carcinoma: a systematic review and meta-analysis. Eur J Radiol 71:164-174

44. Fagotti A, Fanfani F, Rositto C, Lorusso D, De Gaetano AM, Giordano A, Vizzielli G, Scambia G (2008) A treatment selection protocol for recurrent ovarian cancer patients: the role of FDG-PET/CT and staging laparoscopy. Oncology 75:152-158

\section{Publisher's Note}

Springer Nature remains neutral with regard to jurisdictional claims in published maps and institutional affiliations.

\section{Submit your manuscript to a SpringerOpen ${ }^{\circ}$ journal and benefit from:}

- Convenient online submission

- Rigorous peer review

- Open access: articles freely available online

High visibility within the field

- Retaining the copyright to your article

Submit your next manuscript at $\boldsymbol{\nabla}$ springeropen.com 